\title{
ORAL HEALTH RELATED KNOWLEDGE, BEHAVIOR AND QUALITY OF LIFE DIFFERENCES BETWEEN ADOLESCENTS FROM PESANTREN AND NON PESANTREN
}

\author{
Siti Fatimah*, Rosa Amalia**, Bambang Priyono** \\ * Prodi S2 IImu Kedokteran Gigi Fakultas Kedokteran Gigi Universitas Gadjah Mada \\ ** Departemen IImu Kedokteran Gigi Pencegahan dan IImu Kesehatan Gigi Masyarakat Fakultas Kedokteran Gigi \\ Universitas Gadjah Mada \\ Correspondence: sitifatimah.jkg@gmail.com
}

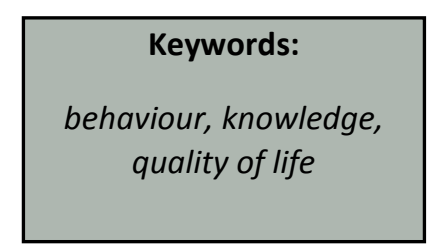

\begin{abstract}
Background: Adolescents from Islamic boarding school adopted simpler life than those not from Islamic boarding school. It can be a trigger of knowledge, behavioural, and oral diseases differences. Neglecting oral diseases will affect the quality daily lives. The aim of this study is to know the differences of oral health related knowledge, behaviour, and quality of life between adolescents from Pesantren and non Pesantren.
\end{abstract}

Method: This study was observational with a cross-sectional design. The study was conducted on 242 adolescents at Madrasah Aliyah Pesantren and non Pesantren in Banjarmasin City, South Kalimantan. The data of research variables were obtained through online questionnaires.

Result: Statistical analysis indicated there were no significant differences of oral health knowledge $(p=0,727>0,05)$ and quality of life $(p=0,711>0,05)$, but there was significant difference of oral health behavior $(p=0,038<0,05)$ between adolescents from Pesantren and non Pesantren. Adolescents from Pesantren have lower oral health behaviour when compared to adolescents from non Pesantren.

Conclusion: The oral health knowledge and quality of life possessed by adolescents from Pesantren were not different from those not from Pesantren. Oral health behavior of adolescents from Pesantren was different than adolescents from non Pesantren. It still needs to be improved.

\section{PENDAHULUAN}

Indonesia menyelenggarakan pendidikan keagamaan Islam dengan satuan lembaga pendidikan berbentuk madrasah, pesantren, dan setiap sekolah umum yang dimiliki organisasi keagamaan Islam. Lembaga pendidikan Islam diharapkan bisa menjadi tempat untuk mengajarkan kebersihan berdasarkan ajaran agama Islam, disamping sebagai tempat memperoleh keilmuan agama secara umum.
Kebersihan dianggap sebagai sebagian dari iman, sehingga saat seseorang mempraktikkan kebersihan dalam kehidupan sehari-hari akan dimaknai sebagai sebagian keutuhan imannya telah terpenuhi.(1-3)

Remaja menjadi salah satu kelompok yang berisiko tinggi memiliki permasalahan kesehatan. Konsekuensi yang ditimbulkan dari faktor sosial, lingkungan, dan perilaku akan menjadi suatu ancaman besar terhadap kesehatan.(4) Pada 
kesehatan gigi dan mulut, ancaman tersebut dapat dihindari melalui penerapan pemeliharaan kebersihan gigi dan mulut dengan benar dan tepat.(5)

Tindakan pemeliharaan kebersihan gigi yang paling mudah dilakukan sendiri adalah dengan cara menyikat gigi.(6) Riset Kesehatan Dasar 2018 menunjukkan sebesar $98,5 \%$ individu yang berasal dari kelompok usia 15-24 tahun telah menyikat gigi setiap hari, namun hanya sebesar 3,3\% yang menyikat gigi dengan waktu yang benar, terutama di waktu pagi hari.(7) Hasil ini menunjukkan kemungkinan remaja kurang mengetahui dan mempraktikkan waktu menyikat gigi dengan tepat. Kurang tepatnya perilaku menyikat gigi tersebut dapat menyebabkan remaja rentan menderita penyakit gigi dan mulut.(8)

Publikasi penelitian yang membandingkan secara langsung pengetahuan, perilaku dan kualitas hidup terkait kesehatan gigi-mulut antara remaja pesantren dan non pesantren masih sangat jarang ditemukan. Penelitian Handayani dkk. dan Hestieyonini dkk. menunjukkan remaja yang bersekolah di pesantren dengan tingkat pengetahuan, sikap, dan perilaku kesehatan gigi yang baik akan memiliki karies gigi yang rendah, namun hal ini sangat dipengaruhi oleh edukasi kesehatan gigi dan mulut yang diterima remaja pesantren.(1,9) Kartikasari dkk. menyebutkan permasalahan yang dihadapi remaja saat tinggal di pesantren yaitu masih terbatasnya fasilitas pemenuhan kebersihan diri yang tersedia, disamping itu kurangnya perhatian remaja terhadap kebersihan diri juga menjadi suatu pemicu yang dapat menimbulkan permasalahan kesehatan.(10)

Penelitian Ruwanda dkk. menyebutkan remaja dari sekolah umum yang memiliki tingkat pengetahuan dan perilaku kesehatan gigi (menyikat gigi dan diet) yang baik akan berisiko lebih kecil terkena karies gigi.(11) Berdasarkan penelitian
Ruwanda dkk. dan Wulandari dkk. menunjukkan hal tersebut kemungkinan karena remaja dari sekolah umum dapat lebih mudah mengakses informasi kesehatan, serta didukung oleh orang tua yang perhatian dalam meningkatkan perilaku kesehatan gigi dan mulut anak.(11,12) Remaja yang tinggal di rumah juga memiliki keuntungan dapat menggunakan fasilitas pemenuhan kebersihan diri sesuai keinginan, sehingga perawatan kebersihan diri dapat dilakukan lebih maksimal.(10) Hal ini menimbulkan adanya potensi perbedaan pengetahuan dan perilaku kesehatan gigi-mulut antara remaja yang bersekolah di pendidikan Pesantren dan non Pesantren.

Perbedaan pengetahuan dan perilaku akan menyebabkan permasalahan kesehatan gigi-mulut yang dihadapi juga berbeda-beda. Permasalahan kesehatan gigi dan mulut yang sering dialami oleh remaja yaitu karies gigi dan penyakit periodontal.(13) Karies yang telah melibatkan area pulpa dapat menyebabkan rasa sakit yang tidak tertahankan, sedangkan adanya jaringan gusi yang berdarah atau bengkak dapat menimbulkan rasa tidak nyaman di dalam rongga mulut.(14-16) Permasalahan gigi dan mulut tersebut apabila diabaikan maka besar kemungkinan menimbulkan gangguan yang dapat membatasi aktivitas dalam kehidupan sehari-hari remaja, sehingga penyakit gigi-mulut yang dirasakan dikatakan dapat memengaruhi kualitas hidup seseorang. $(14,16,17)$

Tujuan penelitian ini adalah untuk mengetahui perbedaan pengetahuan, perilaku, dan kualitas hidup yang berhubungan dengan kesehatan gigi-mulut antara remaja di Pendidikan Pesantren dan non Pesantren di Kota Banjarmasin Kalimantan Selatan.

\section{METODE PENELITIAN}

Jenis penelitian ini adalah kuantitatif observasional denga rancangan penelitian cross- 
setional. Penelitian ini dilaksanakan pada bulan September - Oktober 2020 dan sebelumnya sudah mendapat surat keterangan kelaikan etik dari Komisi Etik Penelitian Fakultas Kedokteran Gigi Universitas Gadjah Mada No.00510/KKEP/FKG-UGM/EC/2020.

Subjek penelitian diambil dengan teknik purposive sampling. Pada penelitian ini total subjek penelitian yang berpartisipasi sebanyak 242 responden, terbagi menjadi 110 responden berasal dari Madrasah Aliyah Pondok Pesantren AlIstiqamah dan 132 responden berasal dari Madrasah Aliyah Negeri 3, Kota Banjarmasin, Kalimantan Selatan. Adapun kriteria inklusi responden dalam penelitian ini, meliputi: 1) remaja usia 15-18 tahun; 2) pelajar Madrasah Aliyah; dan 3) terdaftar sebagai peserta didik di pendidikan keagamaan Islam tempat dilaksanakannya penelitian. Kriteria eksklusi responden dalam penelitian ini yaitu tidak bersedia berpartisipasi sebagai responden penelitian.

Data penelitian dikumpulkan menggunakan kuesioner yang diisi secara online melalui media google form. Tautan google form kuesioner penelitian dibagikan oleh guru/wali kelas masingmasing Madrasah Aliyah kepada responden. Sebelumnya kuesioner penelitian telah diuji validitas dan reliabilitasnya. Hasil uji validitas diperoleh nilai $r$ hitung $\geq 0,3$ sehingga pertanyaan dinyatakan valid. Hasil uji reliabilitas diperoleh nilai alpha cronbach $\geq 0,6$ sehingga pertanyaan dalam penelitian ini dinyatakan reliabel.(18)

Pengetahuan kesehatan gigi-mulut diukur menggunakan kuesioner yang terdiri dari 14 aitem pernyataan. Setiap pernyataan memiliki 3 respon jawaban. Pernyataan favorable dengan respon jawaban "benar" (skor 1), "salah" (skor 0), dan "tidak tahu" (skor 0). Pernyataan unfavorable dengan respon jawaban "benar" (skor 0), "salah" (skor 1), dan "tidak tahu" (skor 0). Total skor diperoleh dengan menjumlahkan seluruh skor aitem pengetahuan kesehatan gigi-mulut. Skor terendah 0, sedangkan skor tertinggi 14 .

Perilaku kesehatan gigi-mulut diukur menggunakan kuesioner yang terdiri dari 19 aitem pernyataan. Setiap pernyataan memiliki 4 respon jawaban berbentuk skala Likert. Pernyataan favorable dengan respon jawaban "selalu" (skor 4), "sering" (skor 3), "jarang" (skor 2), dan "tidak pernah" (skor 1). Pernyataan unfavorable dengan respon jawaban "selalu" (skor 1), "sering" (skor 2), "jarang" (skor 3), dan "tidak pernah" (skor 4). Total skor diperoleh dengan menjumlahkan seluruh skor aitem perilaku kesehatan gigi-mulut. Skor terendah 19, sedangkan skor tertinggi 76 .

Kualitas hidup terkait kesehatan mulut diukur menggunakan kuesioner Oral Health Impact Profile 14 (OHIP-14) versi Indonesia yang terdiri dari 14 aitem pertanyaan. Setiap pertanyaan memiliki 5 respon jawaban berbentuk skala Likert, yaitu "tidak pernah" (skor 0), "hampir tidak pernah" (skor 1), "kadang-kadang" (skor 2), "cukup sering" (skor 3), dan "sangat sering" (skor 4). Total skor diperoleh dengan menjumlahkan seluruh skor aitem OHIP14. Skor terendah 0 , sedangkan skor tertinggi 56. Skor OHIP-14 yang rendah mengindikasikan kualitas hidup terkait kesehatan mulut yang tinggi, begitupun sebaliknya.(19) Variabel penelitian dianalisis menggunakan uji parametrik Independent t-test.(20)

\section{HASIL PENELITIAN}

Tabel 1 menunjukkan karakteristik demografi subjek penelitian, dimana remaja yang berasal dari pendidikan Pesantren maupun non Pesantren memiliki responden dengan mayoritas usia 16 tahun dan jenis kelamin perempuan. Mayoritas remaja Pesantren yang berpartisipasi dalam penelitian ini berasal dari kelas $X$ untuk pendidikan 
Pesantren dan kelas $\mathrm{XI}$ untuk pendidikan non Pesantren.

Tabel 2 menunjukkan nilai rerata, simpangan baku, batas bawah dan batas atas, serta skor terendah variabel pengetahuan dan perilaku kesehatan gigi-mulut remaja dari pendidikan Pesantren ditemukan lebih rendah dibandingkan dengan remaja dari pendidikan non Pesantren. Pada variabel kualitas hidup terkait kesehatan mulut ditemukan nilai rerata, simpangan baku, batas bawah dan batas atas yang diperoleh remaja pendidikan Pesantren lebih tinggi dibandingkan dengan remaja pendidikan non Pesantren, akan tetapi skor terendah dan skor tertinggi yang diperoleh remaja Pesantren ditemukan lebih rendah jika dibandingkan dengan remaja non Pesantren.

Tabel 1. Karakteristik demografi subjek penelitian

\begin{tabular}{lcc}
\hline \multicolumn{1}{c}{ Karakteristik } & \multicolumn{2}{c}{ Jumlah $\mathbf{n}(\%)$} \\
\cline { 2 - 3 } Demografi & Pesantren & Non Pesantren \\
\hline Usia: & $27(24,5)$ & $35(25,5)$ \\
15 tahun & $39(35,5)$ & $50(37,9)$ \\
16 tahun & $32(29,1)$ & $40(30,3)$ \\
17 tahun & $12(10,9)$ & $7(5,3)$ \\
\hline Jenis Kelamin: & & \\
Laki-laki & $42(38,2)$ & $54(40,9)$ \\
Perempuan & $68(61,8)$ & $78(59,1)$ \\
\hline Kelas: & $39(35,5)$ & $37(28,0)$ \\
X & $36(32,7)$ & $50(37,9)$ \\
XI & $35(31,8)$ & $45(34,1)$ \\
XII & $110(100)$ & $132(100)$ \\
\hline Total &
\end{tabular}

Tabel 2. Deskripsi Variabel Penelitian

\begin{tabular}{lccccc}
\hline Variabel Penelitian & Kelompok & Mean \pm SD & 95\% Cl & Minimum & Maximum \\
\hline Pengetahuan & Pesantren & $6,47 \pm 2,437$ & $6,01-6,93$ & 1 & 12 \\
\cline { 2 - 6 } kesehatan gigi-mulut & Non Pesantren & $6,58 \pm 2,459$ & $6,16-7,01$ & 2 & 12 \\
\hline Perilaku kesehatan & Pesantren & $47,44 \pm 6,125$ & $46,28-48,59$ & 31 & 61 \\
\cline { 2 - 6 } gigi-mulut & Non Pesantren & $49,10 \pm 6,233$ & $48,03-50,17$ & 36 & 63 \\
\hline Kualitas hidup terkait & Pesantren & $25,20 \pm 8,863$ & $23,53-26,87$ & 1 & 43 \\
\cline { 2 - 6 } kesehatan mulut & Non Pesantren & $24,76 \pm 9,533$ & $23,12-26,40$ & 2 & 49
\end{tabular}

Keterangan : Mean, rerata tiap kelompok; SD (Standard Deviasi), simpangan baku; $95 \% \mathrm{Cl}$ (Confidence Interval), batas bawah dan batas atas kemungkinan rerata sampel dalam populasi sebenarnya pada tingkat kepercayaan 95\%; Minimum, skor terendah dalam kelompok; Maximum, skor tertinggi dalam kelompok

Tabel 3. Hasil Independent t-test

\begin{tabular}{|c|c|c|c|c|}
\hline Variabel Penelitian & Kelompok & $t$ & $p$ & $\begin{array}{c}\text { Mean } \\
\text { Difference }\end{array}$ \\
\hline Pengetahuan kesehatan gigi-mulut & $\begin{array}{c}\text { Pesantren } \\
\text { Non Pesantren }\end{array}$ & $-0,350$ & 0,727 & $-0,111$ \\
\hline Perilaku kesehatan gigi-mulut & $\begin{array}{c}\text { Pesantren } \\
\text { Non Pesantren }\end{array}$ & $-2,082$ & 0,038 & $-1,662$ \\
\hline Kualitas hidup terkait kesehatan mulut & $\begin{array}{c}\text { Pesantren } \\
\text { Non Pesantren }\end{array}$ & 0,371 & 0,711 & 0,442 \\
\hline
\end{tabular}

Keterangan : $t$, nilai $t$ hitung; $p$, nilai signifikansi; Mean difference, perbedaan rerata antar kelompok

Tabel 3 hasil Independent t-test menunjukkan tidak ada perbedaan yang bermakna pada pengetahuan kesehatan gigi-mulut $(p=0,727>0,05)$ dan kualitas hidup terkait kesehatan mulut $(p=0,711>0,05)$ antara remaja di
Pendidikan Pesantren dan non Pesantren, namun ada perbedaan yang bermakna perilaku kesehatan gigi-mulut $(p=0,038<0,05)$ antara remaja di pendidikan Pesantren dan non Pesantren. Perbedaan rerata antar kelompok mengindikasikan 
remaja kelompok pesantren memiliki perilaku kesehatan gigi-mulut yang lebih rendah dibandingkan remaja kelompok non Pesantren.

\section{DISKUSI}

Pada penelitian ini menunjukkan tidak terdapat perbedaan pengetahuan kesehatan gigimulut antara remaja dari Pendidikan Pesantren dan non Pesantren. Tidak adanya perbedaan kemungkinan disebabkan oleh kesamaan faktorfaktor yang membantu remaja dalam memperoleh dan memproses informasi kesehatan. Faktor-faktor tersebut meliputi peran orang tua, teman sebaya, media informasi kesehatan yang tersedia, dan kegiatan sosial diluar jam belajar formal yang diikuti remaja.(21-23) Hal ini akan memengaruhi penerimaan dan pemahaman remaja terhadap informasi baru. $(9,23)$

Hasil penelitian terdahulu yang mendukung penelitian ini menyebutkan tidak terdapat perbedaan pengetahuan kesehatan gigi-mulut antara remaja dari sekolah umum dan swasta.(24) Sekolah menjadi tempat untuk menyampaikan pendidikan kesehatan. Pendidikan disampaikan melalui program kesehatan yang bekerjasama dengan instansi kesehatan setempat dan kurikulum pembelajaran di sekolah. Hal ini diharapkan dapat meningkatkan pengetahuan kesehatan peserta didik. $(25,26)$

Adanya perbedaan perilaku kesehatan gigimulut kemungkinan karena lingkungan sosialbudaya yang menyebabkan individu dapat memiliki respon yang berbeda-beda mengenai kesehatan. Pada teori perkembangan manusia dikatakan bahwa perilaku seseorang dipengaruhi oleh lingkungan budaya tempat seseorang tinggal, hidup dan berkembang, serta berinteraksi. Pada sistem masyarakat yang lebih kecil (keluarga, teman sebaya, dan sekolah) budaya akan dianggap sebagai bagian dari tindakan dan rutinitas yang lumrah ditemui dalam kehidupan bermasyarakat sehari-hari.(27)

Hasil penelitian ini sejalan dengan penelitian terdahulu yang menyatakan ada perbedaan perilaku kebersihan perorangan antara remaja yang non mukim dan mukim di Pesantren. Remaja yang tinggal di rumah (non mukim) dapat merawat kebersihan diri secara maksimal dibandingkan remaja yang tinggal di pondok pesantren (mukim). Pada penelitian terdahulu tersebut perbedaan lebih ditekankan karena sarana dan prasarana penunjang kebersihan diri yang tersedia di masingmasing tempat tinggal berbeda.(10)

Pada penelitian ini ditemukan rerata skor perilaku kesehatan gigi-mulut remaja kelompok Pesantren lebih rendah dibandingkan remaja kelompok non Pesantren. Hal tersebut kemungkinan karena walaupun pembelajaran kebersihan berdasarkan ilmu agama telah diajarkan di Pesantren, namun jarang diimplementasikan kedalam tindakan sehari-hari. Islam mengajarkan kebersihan merupakan sebagian dari iman, akan tetapi masalah kesehatan bukan dianggap sebagai masalah besar sehingga permasalahan ini masih sering ditemukan di Pesantren.(28)

Pada penelitian ini menunjukkan tidak terdapat perbedaan kualitas hidup terkait kesehatan mulut antara remaja di Pendidikan Pesantren dan non Pesantren. Tidak adanya perbedaan kualitas hidup terkait kesehatan mulut kemungkinan disebabkan oleh persamaan karakteristik subjek penelitian yang sama-sama terwakili di masing-masing kelompok sampel, karakteristik yang dimaksud yaitu usia subjek penelitian. Rentang usia dalam penelitian ini 15 - 18 tahun yang termasuk dalam kelompok usia remaja madya. Permasalahan kesehatan yang mungkin dihadapi pada usia tersebut tidak jauh berbeda. Hal ini didukung oleh penelitian Schuch et al. yang 
menyatakan tidak terdapat perbedaan kualitas hidup terkait kesehatan mulut antara anak dengan rentang usia 8 - 10 tahun.(29)

Hasil ini sejalan dengan beberapa penelitian terdahulu, dimana ditemukan tipe sekolah negeri atau swasta tidak memengaruhi perbedaan kualitas hidup anak. Munculnya penyakit gigi dan mulut lah yang akan menyebabkan gangguan. Gangguan tersebut akan memengaruhi kualitas hidup terkait kesehatan mulut remaja. Kondisi kesehatan gigi dan mulut yang buruk akan diikuti oleh kualitas hidup terkait kesehatan mulut yang rendah.(30-32)

Perlu diketahui bahwa meskipun risiko penyakit gigi dan mulut akan meningkat seiring berjalannya waktu serta akan mengarah ke kualitas hidup terkait kesehatan mulut yang rendah, namun seiring dengan bertambahnya usia individu maka diharapkan individu dapat lebih banyak mengetahui dan mempelajari informasi terkait kesehatan gigi dan mulut.(33,34) Hal ini bertujuan agar individu memiliki kemampuan dalam mengatasi rasa sakit berdasarkan pengalaman yang dimiliki, baik melalui tindakan pencegahan maupun perawatan kesehatan gigi dan mulut.(13,32)

Penelitian ini tidak terlepas dari beberapa keterbatasan penelitian, meliputi: 1) tidak diperiksanya status gigi dan mulut remaja, sehingga tidak dapat mengetahui permasalahan kesehatan gigi-mulut yang sedang dialami remaja saat penelitian dilaksanakan; 2) penelitian ini berdesain cross-sectional, sehingga hanya dapat meprediksi faktor-faktor yang menjadi penyebab ada atau tidak adanya perbedaan.

Saran yang dapat diberikan untuk Lembaga Pendidikan Pesantren adalah masih perlunya penyelenggaraan program-program kesehatan gigi dan mulut secara berkala, yang didalamnya didukung keterlibatan seluruh elemen yang ada di Madrasah Aliyah Pesantren seperti tokoh agama, pengasuh, dan pengajar, serta peserta didik
Pesantren itu sendiri bekerjasama dengan instansi kesehatan setempat. Selain itu, diharapkan baik Madrasah berbasis Pesantren dapat mewujudkan nilai-nilai Islam terkait kesehatan ke dalam suatu sistem, sehingga dapat diaplikasikan dalam kehidupan sehari-hari di Madrasah. Mari bersinergi untuk mewujudkan terciptanya kesehatan di lingkungan Pesantren agar pendidikan Pesantren tidak hanya dijadikan teladan dalam mengajarkan pendidikan agama saja tetapi juga teladan dalam mengajarkan melindungi diri dari berbagai risiko penyakit, termasuk penyakit gigi dan mulut.

\section{KESIMPULAN}

Pengetahuan dan kualitas hidup terkait kesehatan gigi-mulut remaja Pesantren tidak berbeda dengan remaja non Pesantren. Perilaku kesehatan gigi-mulut remaja Pesantren berbeda dengan remaja non Pesantren. Pada remaja Pesantren perilaku kesehatan gigi-mulut ditemukan masih kurang baik, sehingga masih perlu ditingkatkan lagi upaya promotif dan preventif kesehatan gigi-mulut dengan melibatkan seluruh elemen yang ada di Madrasah Aliyah Pesantren tersebut.

\section{DAFTAR PUSTAKA}

1. Handayani $\mathrm{H}$, Arifah $\mathrm{AN}$. The relation of oral and dental health knowledge, attitude and behavior to the dental health status of student at SMP / Mts Pondok Pesantren Putri Ummul Mukminin. Makassar Dent J. 2013;5(2):44-50.

2. Mariana A. Ketika Allah SWT Lebih Menyayangi Wanita. Bandung: Ruabf Kata; 2011. $19 \mathrm{p}$.

3. Machfutra ED, Noor A, Luxiarti R, Mutmainah NF. Hygienic and Healthy Behaviour of Female Islamic Boarding House. 2018;21(4):236-46.

4. DiClemente RJ, Hansen WB, Ponton LE. Handbook of adolescent health risk behavior. Springer Science \& Business Media; 2013. 1-2 p.

5. Al Subait AA, Alousaimi M, Geeverghese A, Ali A, El Metwally A. Oral health knowledge, 
attitude and behavior among students of age 10-18 years old attending Jenadriyah festival Riyadh; a cross-sectional study. Saudi J Dent Res. 2016;7(1):45-50.

6. McDonald RE, Avery DR, Dean JA. McDonald and Avery Dentistry for the Child and Adolescent. United Kingdom: Mosby; 2011.

7. Kemenkes RI. Laporan Nasional Riskesdas 2018. Jakarta: Badan Penelitian dan Pengembangan Kesehatan Kementerian Kesehatan Rl; 2018. 181-220 p.

8. De Silva AM, Gkolia P, Carpenter L, Cole D. Developing a model to assess communitylevel risk of oral diseases for planning public dental services in Australia. BMC Oral Health. 2016;16(45):1-13.

9. Hestieyonini $\mathrm{H}, \mathrm{Y}$ RWE, Meilawaty $\mathrm{Z}$. Perilaku menjaga kesehatan gigi dan mulut pada santri pondok pesantren al-azhar jember. :17-20.

10. Kartikasari A, Fatimawati I. Perbedaan Personal Hygiene pada Siswa Remaja Pondok dan yang Pulang ke Rumah di Madrasah Aliyah Hasan Munadi Desa Banggle Beji Pasuruan Tahun 2015. Medica Majapahit. 2015;7(2):32-42.

11. Ruwanda RA, Basid A. Faktor-Faktor Yang Berhubungan Dengan Status Karies Gigi Pada Anak Sekolah Min 1 Kota Banjarmasin. J Kesehat Indones. 2019;9(3):149-56.

12. Wulandari NNF, Handoko SA, Kurniati PDY. Determinan Perilaku perawatan kesehatan gigi dan mulut pada anak usia 12 tahun di wilayah kerja Puskesmas I Baturiti. Intisari Sains Medis. 2018;9(3):55-8.

13. Silk H, Kwok A. Addressing Adolescent Oral Health: A Review. Pediatr Rev. 2019;38(2):61-8.

14. Karamoy Y. The Relationship Of Dental And Mouth Disease With The Quality Of Life Of Children In Talawaan Minahasa SubDistrict. J Kesehat Masy Andalas. 2017;11(2):115-9.

15. Kozmhinsky VM da R, Heimer M, Sávio P, Goes A De. Sociodemographic Factors and Oral Health Conditions Related to the Impact on the Quality of Life of Adolescents. Brazilian Res Pediatr Dent Integr Clin. 2016;16(1):35-42.

16. Zanatta FB, Ardenghi TM, Antoniazzi RP, Militz T, Pinto P. Association between gingival bleeding and gingival enlargement and oral health-related quality of life ( OHRQoL ) of subjects under fixed orthodontic treatment: a cross-sectional study Association between gingival bleeding and gingival enlargement and or. BMC Oral
Health. 2012;12(53):1-9.

17. Malele-Kolisa $\mathrm{Y}$, Yengopal $\mathrm{V}$, Igumbor $\mathrm{J}$, Nqcobo CB, Ralephenya T. Systematic review of factors influencing oral healthrelated quality of life in children in Africa. African J Prim Heal care Fam Med. 2019;11(1):1-12.

18. Priyatno D. SPSS 22 Pengolahan Data Terpraktis. Yogyakarta: Andi Publisher; 2014.

19. Slade GD, Nuttall N, Sanders AE, Steele JG, Allen PF, Lahti S. Impacts of oral disorders in the United Kingdom and Australia. $\mathrm{Br}$ Dent J. 2005;198(8):489-93.

20. Dahlan MS. Statistik untuk kedokteran dan kesehatan. Jakarta: Penerbit Salemba; 2014. 61-64 p.

21. Sidik TA. Hubungan media informasi dengan tingkat pengetahuan kesehatan reproduksi pada santri di Pondok Pesantren Darut Taqwa Bulusan Semarang. J Kesehat Masy. 2015;3(3):936-44.

22. Yuda DI, Prihanto JB. KESEHATAN ANTARA DI SEKOLAH UMUM DENGAN SEKOLAH BERBASIS AGAMA. J Pendidik Olahraga dan Kesehat. 2017;05(01):140-4.

23. Agustini A. Promosi Kesehatan. Yogyakarta: Deepublish; 2014. 9-21 p.

24. Gupta T, Sequeira P, Acharya S. Oral health knowledge, attitude and practices of a 15year-old adolescent population in Southern India and their social determinants. Oral Health Prev Dent. 2012;10(4):345-54.

25. Aprilian YD, Prihanto JB. Perbandingan Perilaku Hidup Sehat antara Siswa SMP Negeri 2 Wonoayu dengan SMP Ulul Albab. $J$ Pendidik Olahraga dan Kesehat. 2016;4(2):384-9.

26. Sari IPT. Pendidikan kesehatan sekolah sebagai proses perubahan perilaku siswa. $J$ Pendidik Jasm Indones. 2013;9(2):141-7.

27. Vélez-Agosto NM, Soto-Crespo JG, Vizcarrondo-Oppenheimer M, Vega-Molina S, García Coll C. Bronfenbrenner's bioecological theory revision: Moving culture from the macro into the micro. Perspect Psychol Sci. 2017;12(5):900-10.

28. Jannah R. Faktor budaya yang mempengaruhi perilaku bersih di Pesantren: Kajian terhadap kultur Pesantren yang mempengaruhi tingkat kesehatan santri. J IImu Teknol Kesehat. 2016;4(1):9-22.

29. Schuch HS, dos Santos Costa F, Torriani DD, Demarco FF, Goettems ML. Oral health-related quality of life of schoolchildren: impact of clinical and psychosocial variables. Int J Paediatr Dent. 2015;25(5):358-65. 
30. Scarpelli AC, Paiva SM, Viegas CM, Carvalho AC, Ferreira FM, Pordeus IA. Oral health-related quality of life among $B$ razilian preschool children. epidemiology. Community Dent oral. 2013;41(4):336-44.

31. Carvalho AC, Paiva SM, Viegas CM, Scarpelli AC, Ferreira FM, Pordeus IA. Impact of malocclusion on oral healthrelated quality of life among Brazilian preschool children: a population-based study. Braz Dent J. 2013;24(6):655-61.

32. Chukwumah NM, Folayan MO, Oziegbe EO, Umweni AA. Impact of dental caries and its treatment on the quality of life of 12-to 15- year-old adolescents in $\mathrm{B}$ enin, $\mathrm{N}$ igeria. Int J Paediatr Dent. 2016;26(1):66-76.

33. Baker SR, Mat A, Robinson PG. What psychosocial factors influence adolescents' oral health? J Dent Res. 2010;89(11):12305.

34. Freire-Maia FB, Auad SM, de Abreu MHNG, Sardenberg F, Martins MT, Paiva SM, et al. Oral health-related quality of life and traumatic dental injuries in young permanent incisors in Brazilian schoolchildren: a multilevel approach. PLoS One. 2015;10(8):1-18. 